\title{
Chesapeake Bay acidification: relative impacts of long-term local and global stressors
}

\author{
Fei DA ${ }^{1}$, MARJorie A. M. Friedrichs ${ }^{1}$, PIERre St- \\ LAURENT $^{1}$, ELIZABETH H. SHADWICK ${ }^{1,2}$, AND RAYMOND \\ NAJJAR ${ }^{3}$ \\ ${ }^{1}$ Virginia Institute of Marine Science, Gloucester Point, VA \\ 23062 (*correspondence: fda@vims.edu) \\ ${ }^{2}$ CSIRO, Battery Point TAS 7004, Australia \\ ${ }^{3}$ The Pennsylvania State University, State College, PA 16801
}

Multiple anthropogenic stressors have been impacting the Chesapeake Bay carbonate $\left(\mathrm{CO}_{2}\right)$ system over the past several decades. These include global-scale increases in atmospheric temperature and $\mathrm{CO}_{2}$ concentration, and local-scale changes in riverine nutrients and alkalinity. Because these stressors impact physical and biogeochemical processes, the Bay $\mathrm{CO}_{2}$ system is likely to undergo complex long-term changes that are challenging to study via analysis of in-situ data alone. Historical $\mathrm{pH}$ data collected since 1996 showed surface $\mathrm{pH}$ has been decreasing with rates of up to $-0.08 \mathrm{pH}$ unit decade ${ }^{-1}$ from May to September. Global increases in atmospheric $\mathrm{CO}_{2}$ concentration are expected to decrease $\mathrm{pH}$ by $-0.02 \mathrm{pH}$ unit decade $^{-1}$; however, it is difficult to quantify the impacts of other stressors (e.g. changing nutrients) on $\mathrm{pH}$ trends. We examine and identify the primary drivers of this long-term trend in Chesapeake Bay $\mathrm{CO}_{2}$ system using a 3D physicalbiogeochemical estuarine model. A reference simulation is conducted from 1985-1989. Sensitivity simulations conducted from 2015 to 2019 are used to study the global vs. local stressors that are responsible for the changes in $\mathrm{CO}_{2}$ system over 30 years. Model results indicate that global increases in atmospheric $\mathrm{CO}_{2}$ concentration and local reductions in nitrogen loading are two primary stressors causing similar long-term changes in Chesapeake Bay $\mathrm{CO}_{2}$ system. Increased atmospheric $\mathrm{CO}_{2}$ and temperature together reduced surface $\mathrm{pH}$ and aragonite saturation state $(\Omega)$ by 0.2 units and 0.4 over 30 years, respectively. Reduced riverine inorganic and organic nitrogen concentrations result in similar decreases in surface $\mathrm{pH}$ and $\Omega$, indicating that nutrient management efforts in the Bay watershed may be exacerbating acidification in surface waters; however, nutrient reduction may improve bottom $\mathrm{pH}$ in the deep mainstem due to decreased respiration. In comparison, long-term increases in riverine alkalinity and dissolved inorganic carbon inputs, together, barely impact surface $\mathrm{pH}$ while increase surface $\Omega$ by 0.1 . This work suggests that a complex combination of global and local anthropogenic stressors are responsible for observed longterm $\mathrm{CO}_{2}$ system changes in estuarine systems. 